\title{
Unprotected Sex and Associated Factors among Adolescent Students of Rift Valley University Jimma Campus, Jimma Town, South West Ethiopia: Institution Based Cross Sectional Study
}

\author{
Million Abera \\ School of Nursing and Midwifery, Faculty of Health Sciences, Institute of Health, Jimma University, Jimma, Ethiopia \\ Email address: \\ megaabera@gmail.com, million_abera@yahoo.com
}

\section{To cite this article:}

Million Abera. Unprotected Sex and Associated Factors Among Adolescent Students of Rift Valley University Jimma Campus, Jimma Town, South West Ethiopia: Institution Based Cross Sectional Study. International Journal of HIV/AIDS Prevention, Education and Behavioural Science. Vol. 5, No. 1, 2019, pp. 1-10. doi: 10.11648/j.ijhpebs.20190501.11

Received: December 10, 2018; Accepted: January 2, 2019; Published: January 29, 2019

\begin{abstract}
Unprotected sex is a sex-related risk behavior that contributes to pregnancy and sexually transmitted disease transmission amongst adolescents. Adolescents have high rates of unprotected sex and sexually transmitted diseases, and they are at increased risk for adverse behaviors and outcomes. Establishing risk factors for unprotected sex in adolescents is one of the essential steps in developing primary and secondary prevention programs in universities and communities. However there is lack of information on unprotected sex and associated factors among private university adolescents in the study area. Thus, the aim of this study was to assess the effects of associated factors on unprotected sex among adolescent students of Rift Valley University Jimma campus, Jimma town, South West Ethiopia. Institutional based cross-sectional study was employed from November 06 - 21, 2017. Five hundred twenty three (523) adolescent students of Rift Valley University Jimma campus were selected using a simple random sampling technique. Data were collected using a pre-tested, structured, self-administered questionnaire and analyzed using SPSS version 20. Multivariate logistic regression was conducted to identify the independent predictors of unprotected sex at $95 \%$ CI and P-value less than 0.05 . The study revealed that $40.4 \%$ of respondents were sexually experienced. Majority (74.3\%) reported having had sex with only one lifetime partner and $131(63.6 \%)$ had used condom during sex before. Majority (56.3\%) of the sexually experienced respondents were sexually active within 12 months of study. Up to $28.4 \%$ of sexually experienced respondents have had sex with a person other than their current partner and 44 $(37.9 \%)$ of them did not used condom consistently. Hence, twenty three (19.8\%) of the study participants were reported unprotected sexual practices. Being late age at first sexual intercourse, low parental supervision, visiting night club, and hadn't source of information on sexuality were the significant predictors of unprotected sex within 12 months of study. The findings of this study showed that university students are involved in unprotected sex that may increase their risk of contracting Human Immunodeficiency Virus infection. Based on the above results, researcher recommended the university, families and zonal education office and other stakeholders should be involved and working in collaboration to reduce the unprotected sexual practice.
\end{abstract}

Keywords: Unprotected Sex, Sexual Behavior, Condom Use, Rift Valley University, Jimma

\section{Introduction}

Sexuality issues have been one of the most fundamental aspects of human existence, which is directly related to both the physical and psychosocial well-being of an individual [1]. Particularly, the health of adolescents is greatly dogged by their behavior, and sexuality is an important and complex area of adolescent behavioral health. Adolescents are at high danger to practice unprotected sexual behaviors and reproductive health problems. But these problems are not considered health priorities by assuming these people have lower morbidity, mortality and good knowledge than older and adult age groups [2]. According to World health organization (WHO), adolescence is defined as that period of psychosexual 
developments between the onset of sexual maturity (puberty) and early adulthood; this includes period between the ages of 10 and 19 years [1]. Today, there are more than one billion adolescents, $70 \%$ of who live in developing nations. Adolescents are exposed to unsafe and early sex especially in developing countries and therefore there is the risk of unwanted pregnancy, unsafe abortion and sexually transmitted infections (STIs) including HIV \AIDS [3]. Unprotected sexual activity carries with it risks to reproductive health at any age but most particularly during adolescence, because the risks of infection are greater when full physical maturation is incomplete [4].

Sexual activities among adolescents have been reported to be increasing worldwide, particularly in Sub-Saharan Africa adolescents have at high burden sexual risks and increasing unprotected sexual activities [5]. In Ethiopia, an increasingly large number of adolescents are enrolled in both private and government universities, and almost $60 \%$ of youths in colleges and high school reported having sex, there were about 750,000 pregnancies among youths of age $15-19$, and $67 \%$ of pregnancies were unplanned [6] as well as $0.4 \%$ of adolescents were infected with HIV [7]. The third baseline assessment of mobile HIV counseling and testing program in Ethiopia showed that most-at-risk populations were high school and college youths. Similarly in the study area from the most at risk populations, $70.5 \%$ of them were in- school youth and college student of which $35.9 \%$ were from college and involved in unprotected sexual activities [8-10]. The Longitudinal Family Survey of Youth in Jimma indicated that alcohol consumption and drug use for adolescents are associated with increases in early sexual activities, sex with commercial sex workers and unprotected sex [7, 11]. In general college youths are highly affected by many sexual and nonsexual consequences, including HIV/AIDS or STI, unwanted pregnancy, abortion, poor school performance, high dropout rate, psycho-social problems, conduct disorder and economic problems [8]. Still developing research in detail on unprotected sex and risky sexual behaviors among adolescents and recommend practical strategies accordingly was pointed out as an important interventional tool to achieve UNAIDS goal among adolescents in Ethiopia [12]. Besides, little is known about unprotected sex and other risky sexual behaviors among adolescents, many of the studies are not up-to-date, as well as behavior is dynamic in nature, in which this study gives the present image of unprotected sexual behavior in Jimma Zone. Therefore, this study assessed the practice of unprotected sex and associated factors among private university adolescents in Jimma town.

\section{Method}

\subsection{Study Design and Setting}

An institution-based cross sectional study was employed at Rift Valley University Jimma campus from November 06 21, 2017, Jimma town, south west Ethiopia, Oromia regional state. Jimma town is the capital of Jimma zone, South west Ethiopia, Oromia regional state which is located at $357 \mathrm{Kms}$ to the south west of Addis Ababa. The area lies between a latitude of $7^{\circ} 41^{\prime} \mathrm{N}$ and longitude of $36^{\circ} 50^{\prime} \mathrm{E}$ and has an elevation of 1704 meters above sea level, with a total population of 159,009 of whom 80,897 were males and 78,112 were females [13]. There are two universities which are one governmental (Jimma University) and one privately owned (Rift Valley University) in the town. Rift Valley University was established by five persons in October 2000 G. C. RVU is the largest private university in Ethiopia, with 27 campuses around the country [14]. Of these, RVU Jimma campus offers dozens of TVET (Technical Education and Vocational Training), undergraduates, and graduate programs. Currently the university has a total of 2817 students, excluding the non-regular undergraduate and graduate programs, in six undergraduate departments (Accounting, Business Management, Computer Science, Economics, and Nursing, Public Health) training health and none health science students.

\subsection{Study Population}

The source population was all students aged 15 to 19 years attending the class in the Rift Valley University Jimma campus who had been enrolled in regular program under six different departments during the academic year of 2017. Study population was all sampled regular adolescent students available during the study period. Night shift students, students who will not be able to complete the questionnaire without assistance (having visual, hearing impairments and seriously ill) were excluded from the study for the data quality.

\subsection{Sample Size Determination and Sampling Procedure}

The required sample size was determined using the single population proportion formula with the following assumptions: the expected prevalence of consistent condom use among students who had sex with their regular partner in 12 months prior to the survey of Oromia region estimated to be $29.2 \%$ from Behavioral Surveillance Survey of 2005 among in school youth, which in turn gives the proportion of unprotected sexual practice (UPSP) of $70.8 \%$ [15], confidence level of $95 \%$, and $5 \%$ degree of precision.

A formula is;

$$
n=\frac{(\mathrm{Z} \alpha / 2)^{2} P(1-P)}{d^{2}}
$$

Based on the above formula and assumptions, with an additional $10 \%$ estimated non-response and using design effect of 2, total sample size of the study was 523 adolescent students. Among a total of regular students registered in 2017 academic year under six departments of RVU Jimma campus, 1921 of them were regular students aged 15 to 19 years. The sample sizes for each department was proportionally allocated according to the number of students they had, then the study participant were selected using simple random technique from each department by taking list of students which belongs to selected departments of all years from the office of the registrar. 


\subsection{Data Collection Instrument and Procedure}

A semi-structured, pre-tested, and self-administrated English version questionnaire was used to collect the data. It was initially adapted from similar survey reviews that have been carried out with in the country and amended to local situation [15-17]. The questionnaire had questions of socio demographic, individual, family related, sexual information, and risky sexual behavioral factors. Questionnaire was originally prepared in English, translated into local language (Afan Oromo), and then translated back to English to check consistency before data collection. It was pre-tested on $5 \%$ of the sample in Jimma teachers training college (JTTC) which have similar background. Four nursing diploma graduate were recruited as data collection facilitators and training was given for them for one day a week ahead of the actual data collection period about the data collection tool and how to collect data, and taking informed consent to have common understandings. Every day the filled questionnaires were regularly cross checked for completeness and consistency of information by the principal investigator. Any error, ambiguity, incompleteness, or other problems were addressed immediately before next day's activities. To maximize confidentiality of responses no discussions were permitted between students throughout the process.

\subsection{Measurements}

Result analysis pertaining to this section was guided by the research question: "unprotected sexual practice amongst adolescent students in RVU Jimma campus". Unprotected sex was assessed by different aspects which include condom utilization and sexual partners of adolescents. Two items from the risky sexual behavioral questions which are "consistent condom use during sexual intercourse and type of sexual partner in the past 12 months" were used to assess the participants' engagement in unprotected sex. Finally participants considered as practicing unprotected sex if adolescents reported both having had sexual intercourse with their non-regular partner and did not used condom consistently during sexual intercourse before the survey.

\subsection{Data Processing and Analysis}

Data were coded and entered to computer using Epi Data software version 3.1 (Epi Data Association, Odense, Denmark) and exported to SPSS program version 20.0 for further analysis. Descriptive statistics were calculated to describe data of all variables and for sexually active respondents, unprotected sex was calculated from sexually active students those who didn't used condom consistently during sex with any partner other than regular partner over those eligible times one hundred, then unprotected sex was recorded in to dichotomous variable for analytic purpose. Binary and multivariable logistic regression analyses were used to determine the presence of statistically significant associations between unprotected sex and the independent variables. Crude and adjusted odds ratios with 95\% CI were calculated and a P-value $<0.05$ was considered statistically significant.

\subsection{Ethical Clearance}

The study was reviewed and approved by the ethical review committee (ERC) of the RVU, Jimma campus. Informed consent was obtained from each study participants and their parents (for $<16$ years old students). All participants were informed of their right to refuse at any time and not to write their names to ensure confidentiality. The study was conducted after getting oral consent from the study participants. In order to ensure privacy, male and female respondents were gave their responses in separate rooms. The information provided by each respondent was kept strictly confidential.

\section{Results}

Socio-demographic characteristics of study participants From a total of 523 students who were identified for the study, 510 were involved in the study while 13 refused to participate in the study, yielding a response rate of $97.5 \%$. Participants were included from all of the undergraduate departments with a sample proportional to the total size of each department regular students. Overall, out of 510 respondents, this study revealed that 351 (68.8\%) were females while 369 (72.4\%) were aged between 18-19 years with the mean age of 18 years. About 188 (36.9\%) were attending second year class during the survey. The majority of study participants, $225(44.1 \%), 221(43.3 \%)$, and 435 $(85.3 \%)$ of them were from Oromo ethnicity, followers of Orthodox, and single respectively. Four hundred twenty six $(83.5 \%)$ of the respondents did not have their own job to have income of their own while 21 (38.2\%) have received $>=301$ ETB as pocket money per month from their families. Two hundred forty eight $(48.6 \%)$ were living with their both parents (Table 1).

Table 1. Socio-demographic characteristics among Rift Valley University, Jimma campus adolescent students, Jimma town, November, $2017(n=510)$.

\begin{tabular}{llll}
\hline Variables & Categories & Frequency & Percentages \\
\hline \multirow{2}{*}{ Sex } & Female & 351 & 68.8 \\
Age (in years) & Male & 159 & 31.2 \\
& $\leq 17$ & 141 & 27.6 \\
& $18-19$ & 369 & 72.4 \\
Class year & First & 160 & 31.4 \\
& Second & 188 & 36.9 \\
& Third & 117 & 22.9 \\
& Fourth & 45 & 8.8 \\
Ethnicity & Oromo & 225 & 44.1 \\
& Amhara & 131 & 25.7 \\
& Kefa & 99 & 19.4 \\
& Gurage & 43 & 8.4 \\
& *Others & 12 & 2.4 \\
& Orthodox & 221 & 43.3 \\
Religion & Protestant & 121 & 23.7 \\
& Muslim & 112 & 22.0 \\
& Catholic & 39 & 7.6 \\
& Waqefata & 17 & 3.3 \\
Marital status & Single & 435 & 85.3 \\
& Married & 69 & 13.5 \\
\hline
\end{tabular}




\begin{tabular}{llll}
\hline Variables & Categories & Frequency & Percentages \\
\hline \multirow{4}{*}{ Income of their own } & Divorced & 6 & 1.2 \\
& Yes & 84 & 16.5 \\
& No & 426 & 83.5 \\
& $<=100$ & 16 & 29.1 \\
Pocket money (in ETB) & $101-200$ & 12 & 21.8 \\
& $201-300$ & 6 & 10.9 \\
& $>=301$ & 21 & 38.2 \\
& Both parents & 248 & 48.6 \\
& Mother/Father & 55 & 10.8 \\
Currently living with & Relatives & 82 & 16.1 \\
& Friends/fiancé & 81 & 15.8 \\
& Alone & 44 & 8.6 \\
\hline
\end{tabular}

*Others include: Wolayta, Dawro and Tigre
Family factors of study participants

The majority, 402 (78.8\%) of respondents' average monthly family income was $>=1000$ ETB. One hundred seventy one (33.5\%) and $191(37.5 \%)$ of the respondents' mothers and fathers were attended primary (grade 1-8) and above secondary education respectively. Two hundred sixty four $(51.8 \%)$ of respondents reported that both parents had a job, two hundred twenty five $(44.1 \%)$ of respondents' family live in Jimma town and $60(11.8 \%)$ in rural areas. Four hundred six $(79.6 \%)$ of the respondents were supervised by their parents where they spent their time while others not (Table 2).

Table 2. Family factors among Rift Valley University, Jimma campus adolescent students, Jimma town, November, 2017 ( $n=510)$.

\begin{tabular}{|c|c|c|c|}
\hline Variables & Categories & Frequency & Percentages" \\
\hline \multirow[b]{2}{*}{ Average monthly Family Income (in ETB) } & $0-499$ & 59 & 11.6 \\
\hline & $500-999$ & 49 & 9.6 \\
\hline \multirow{3}{*}{ Family Residential Place } & Jimma town & 218 & 42.7 \\
\hline & Other small towns & 225 & 44.1 \\
\hline & Rural area & 67 & 13.1 \\
\hline \multirow{5}{*}{ Father's Education Level } & Illiterate & 20 & 3.9 \\
\hline & Read and write & 84 & 16.5 \\
\hline & Primary $(1-8)$ & 137 & 26.9 \\
\hline & Secondary (9-12) & 78 & 15.3 \\
\hline & Above Secondary & 191 & 37.5 \\
\hline \multirow{4}{*}{ Mother's Education Level } & Illiterate & 42 & 8.2 \\
\hline & Read and write & 81 & 15.9 \\
\hline & Secondary (grade 9-12) & 129 & 25.3 \\
\hline & Above Secondary & 87 & 17.1 \\
\hline \multirow{4}{*}{ Family Job } & Both of my parents work & 264 & 51.8 \\
\hline & Only my father work & 164 & 32.2 \\
\hline & Only my mother work & 49 & 9.6 \\
\hline & Both of my parents don't work & 33 & 6.5 \\
\hline \multirow{2}{*}{ Parental supervision } & Yes & 406 & 79.6 \\
\hline & No & 104 & 20.4 \\
\hline
\end{tabular}

Sexuality related information of study participants

Out of all respondents, $403(79 \%)$ of the respondents had got information on sexuality and reproductive health. Of these most frequently mentioned sources of information for sexuality and reproductive health were, 181 (31.5\%), 132 (22.9\%), $125 \quad(21.6 \%)$ medias, educational institutions, and health institutions respectively. Regarding availability of youth friendly service in the town, $256(50.2 \%)$ responded the presence of youth friendly service in the town. Three hundred fifty $(68.4 \%)$ of the respondents have discussed sex related issues with their friends, while 413 (81\%) and 360 (70.6\%) never discussed sex related issues with their father and mother at all respectively (Table 3 ).

Table 3. Sexuality related information among Rift Valley University, Jimma campus adolescent students, Jimma town, November, $2017(n=510)$.

\begin{tabular}{|c|c|c|c|}
\hline Variables & Categories & Frequency & Percentages $^{*}$ \\
\hline \multirow{2}{*}{ Having source of information } & Yes & 403 & 79.0 \\
\hline & No & 107 & 21.0 \\
\hline \multirow{6}{*}{ Source of information on sexuality $(\mathrm{n}=578)$} & Medias & 181 & 31.5 \\
\hline & Educational institutions & 132 & 22.9 \\
\hline & Health institutions & 125 & 21.6 \\
\hline & Religious leaders & 79 & 13.6 \\
\hline & Friends/peer & 42 & 7.2 \\
\hline & Parents & 19 & 3.4 \\
\hline
\end{tabular}




\begin{tabular}{llll}
\hline Variables & Categories & Frequency & Percentages $^{*}$ \\
\hline \multirow{2}{*}{ Presence of youth friendly center in the town } & Yes & 254 & 49.8 \\
& No & 256 & 50.2 \\
Discuss with Father & Discussed & 97 & 19.0 \\
& Never discussed & 413 & 81.0 \\
Discuss with Mother & Discussed & 150 & 29.4 \\
& Never discussed & 360 & 70.6 \\
Discuss with Friends & Discussed & 350 & 68.4 \\
\hline
\end{tabular}

Sexual behaviors of the study participants

Overall, this study found that two hundred six (40.4\%) of the students have experienced sexual intercourse in the past. Among those who had experienced sexual intercourse, $144(69.9 \%)$ were below the age of 17 years and the mean $( \pm \mathrm{SD})$ age at first sexual intercourse for both sexes was $16.86( \pm 1.148)$. Of them, $153(74.3 \%)$ reported having had sex with only one lifetime partner and 131 $(63.6 \%)$ had used condom during sexual intercourse before. The majority, 493 (96.7\%), 448 (87.8\%) and 379 $(74.3 \%)$ of respondents have never smoked cigarettes, chewed chat and drunk alcohol respectively. One hundred thirty one $(25.7 \%)$ of all respondent watched pornographic film, $84(16.5 \%)$ of respondents reported that they visited night clubs/parties and $455(89.2 \%)$ of respondents reported that they influenced by peers to do sex. Of the participants who had sexual experience, $153(74.3 \%)$ reported having had sex with only one lifetime partner and131 (63.6\%) had used condom during sexual intercourse before. Among the sexually active students ever, $116(56.3 \%)$ experienced sexual intercourse within the 12 months of this study. Of them, $83(71.6 \%)$ had regular partner, and $44(37.9 \%)$ did not used condom consistently (Table 4).

Table 4. Sexual behaviors among Rift Valley University, Jimma campus adolescent students, Jimma town, November, 2017.

\begin{tabular}{|c|c|c|c|}
\hline Variables & Categories & Frequency & Percentages $^{*}$ \\
\hline \multirow{2}{*}{ Ever practice sex $(\mathrm{n}=510)$} & Yes & 206 & 40.4 \\
\hline & No & 304 & 59.6 \\
\hline \multirow{2}{*}{ Age at first sexual intercourse } & Lowest thru 17 & 144 & 69.9 \\
\hline & $18-19$ & 62 & 30.1 \\
\hline Mean $( \pm \mathrm{SD})$ age at first sexual intercourse & $16.86( \pm 1.148)$ years & & \\
\hline \multirow{2}{*}{ Lifetime Number of sexual partner $(\mathrm{n}=206)$} & One & 153 & 74.3 \\
\hline & Two and more & 53 & 25.7 \\
\hline \multirow{2}{*}{ Condom use ever $(n=206)$} & Yes & 131 & 63.6 \\
\hline & No & 75 & 36.4 \\
\hline \multirow{2}{*}{ Cigarette smoking $(\mathrm{n}=510)$} & Never smoked & 493 & 96.7 \\
\hline & Smoked & 17 & 3.4 \\
\hline \multirow{2}{*}{ Chat chewing $(\mathrm{n}=510)$} & Never chewed & 448 & 87.8 \\
\hline & Chewed & 62 & 12.2 \\
\hline \multirow{2}{*}{ Alcohol drinking $(\mathrm{n}=510)$} & Never drunk & 379 & 74.3 \\
\hline & Drunk & 131 & 25.7 \\
\hline \multirow{2}{*}{ Watching sex films ( $\mathrm{n}=510)$} & Yes & 131 & 25.7 \\
\hline & No & 379 & 74.3 \\
\hline \multirow{2}{*}{ Visiting night clubs/parties $(\mathrm{n}=510)$} & Yes & 84 & 16.5 \\
\hline & No & 426 & 83.5 \\
\hline \multirow{2}{*}{ Peer influence $(\mathrm{n}=510)$} & Yes & 55 & 10.8 \\
\hline & No & 455 & 89.2 \\
\hline \multirow{2}{*}{ Had sex within the past 12 months ( $\mathrm{n}=206$ ) } & Yes & 116 & 56.3 \\
\hline & No & 90 & 43.7 \\
\hline \multirow{2}{*}{ Type of sexual partner before study ( $\mathrm{n}=116)$} & Regular & 83 & 71.6 \\
\hline & Non-regular & 33 & 28.4 \\
\hline \multirow{3}{*}{ Frequency of condom use before study $(\mathrm{n}=116)$} & Rarely & 15 & 12.9 \\
\hline & Occasionally & 29 & 25.0 \\
\hline & Always (consistently) & 72 & 62.1 \\
\hline
\end{tabular}

Unprotected sexual practice of study participants

Among those respondents who had sexual intercourse within 12 months of this study, 33 (28.4\%) had sexual intercourse with their non-regular partner and 44 (37.9\%) did not used condom consistently during sexual intercourse yielding the prevalence of $23(19.8 \%)$ of unprotected sex in 
the last 12 months (Figure 1).

\section{Unprotected Sexual Practice}

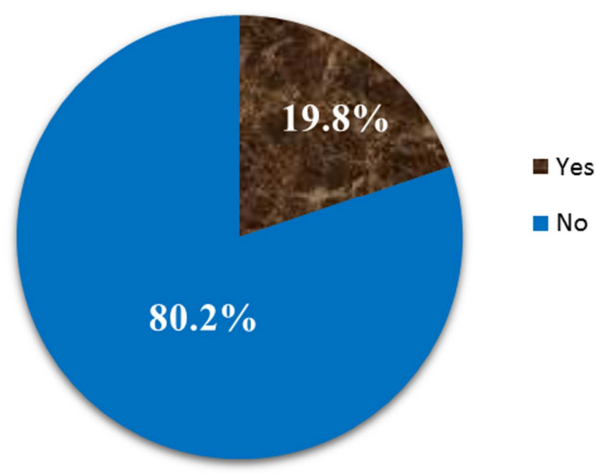

Figure 1. Unprotected sexual practice among Rift Valley University, Jimma campus adolescent students, Jimma town, November, $2017(n=116)$.

Factors associated with unprotected sex of study participants

Logistic regression analysis was performed to identify the effect of independent predictors on unprotected sex with $95 \%$ $\mathrm{CI}$ and P-value less than 0.05 . The final model showed that only parental supervision, visiting night club, having source of information on sexuality and reproductive health, and age at first sexual intercourse were significantly associated with unprotected sexual practice. Thus, adolescents who did not receive parental supervision were five times more likely to practice unprotected sex compared to adolescents who reported receiving parental supervision $[\mathrm{AOR}=5.1,95 \% \mathrm{CI}$ : $(1.3,15.6)]$. The other significant variable was visiting night clubs or parties, those who visited night clubs/parties were four times more likely to practice unprotected sex than those who did not visit $[\mathrm{AOR}=4.6,95 \% \mathrm{CI}$ : $(1.6,16.5)]$. Those students who hadn't got information on sexuality and reproductive health were five times more likely to practice unprotected sex than those who have got information $(\mathrm{AOR}=$ 5.1, 95\% CI: $(1.5,16.9)]$. Age of participants at first sexual intercourse was also important predictor of unprotected sex and the result showed that per a unit increase in total score of age of participants at first sexual intercourse, the odds of unprotected sex is also increased by 2.5 and the observed difference was statistically significant $[\mathrm{AOR}=2.5,95 \% \mathrm{CI}$ $(1.3,5.1)]$. But other variables are not associated significantly with unprotected sex of adolescent students (Table 5).

Table 5. Factors associated with unprotected sex among Rift Valley University, Jimma campus adolescent students, Jimma town, November, 2017 ( $n=116)$.

\begin{tabular}{llllll}
\hline \multirow{2}{*}{ Independent predictors } & & Unprotected Sex & COR (95\%CI) & \multirow{2}{*}{ AOR (95\%CI) } \\
\cline { 2 - 5 } & & No (\%) & Yes (\%) & 1 & 1 \\
Parental Supervision & Yes & $70(75.3)$ & $13(53.5)$ & $3.9(1.5,10.3)^{* *}$ & $5.1(1.3,15.6)^{* *}$ \\
Had source of & No & $23(24.7)$ & $10(43.5)$ & 1 & 1 \\
information & Yes & $71(76.3)$ & $13(56.5)$ & $4.2(1.6,10.9)^{* *}$ & $5.1(1.5,16.9)^{* *}$ \\
Visiting night clubs/parties & No & $22(23.7)$ & $14(60.9)$ & $3.8(1.5,9.8)^{* *}$ & $4.6(1.6,16.5)^{* *}$ \\
*Age at first sexual intercourse & Yes & $27(29.0)$ & $9(39.1)$ & 1 & 1 \\
\hline
\end{tabular}

* Continuous variable

\section{Discussion}

This study provides insight into the operation of unprotected sexual practice of adolescent students in RVU Jimma campus. Generally, $19.8 \%$ of the study participants were experienced unprotected sexual practice (unsafe sex, sexual intercourse with non-regular partner using condom inconsistently within 12 months). Some of the reasons why respondents are at unprotected sexual practice: $28.4 \%$ had sex with non-regular partner and $37.9 \%$ had sex using condom inconsistently within 12 months. This finding is congruent with findings from different high schools in Ethiopia, Tana Haik and Pawi Woreda that showed the prevalence of unsafe sex were $19 \%$ and $20 \%$, respectively $[18,19]$. The possible reasons for a significant numbers of adolescent experienced unprotected sexual practices might be their developmental changes, being young people, living in higher institutions without direct parental supervision, freedom for initiating sexual activity, and lack of awareness about safer sax. This idea can be supported by previous studies; Mcardle P. reported, more young people in higher institutions are getting sexually active and often take advantage of freedom from direct parental supervision and guidance to express their freedom by initiating sexual activity without adequate protection [42], Fatusi AO also stated, young people often face enormous peer's pressure to engage in sex and to watch unlicensed erotic/romantic video films. As a result of this, a significant number of adolescents are involved in sexual activities at an early age and they were at risk to practice unprotected sexual behaviors [20]. Other study done by Dahl RE also noted that during puberty, changes occur in the neuronal system responsible for emotions and motivations, which facilitates the emergence of risk taking behaviors. At this stage, adolescents seek new experiences that generate pleasure, but the feeling of supremacy can trigger a lack of awareness of the consequences of their actions [21].

On the other hand, this finding was higher compared to study in Humera reported, $13.7 \%$ of unprotected sexual intercourse rate [22] and much higher than a study in Southern Taiwan [23] reported, much lower unprotected sexual intercourse rate $(2.1 \%)$. The discrepancy might be due to most private university students were living in a rented 
house away from their supervising families and they were at risk to practice unprotected sexual behaviors. In addition this could be because of socio-behavioral change of the current students. However, finding was much lower than the finding from a private college of Bahir Dar city that showed $41 \%$ of the participants have experienced unprotected sexual practice [24]. This implies most private university students at RVU were elder than private college students of Bahir Dar city which increase students' vulnerability to practice unprotected sexual behaviors. The possible explanation could be due to the difference in the study period and since Bahir Dar city is known highly prevalent city in HIV/AIDS so that Bahir Dar city students were at risk to practice unprotected sexual behaviors.

Regarding having had sex with non-regular partner, $28.4 \%$ had sex with non-regular partner before the survey. This finding is consistent with a study done in Jimma University (28.3\%), Jigjiga University (30.14\%), and Uganda (24.0\%) having had sex with non-regular partner [25-27]. This suggested that many respondents did not adopt safe sexual practices as a result of being a group of young students makes it difficult to adopt safer sex practices and their lack of awareness on safe sex practices such as being faithful. Supporting this idea, study done by Rosiers, et.al stated that, the concentration of same age group peers in college settings may exacerbate risky sexual behaviors [28]. Other study done by Sabone et al. also reported that university students are at the stage of physiological and psycho-social development in which sexual urges and activities are difficult to contain [29]. However, this figure is high than in Haramaya, that showed $11.5 \%$ of adolescent had non-regular partner in the last 12 months (30). On the other hand this figure is lower than study in Tana (34\%), Pawi Wereda high school students (35\%), Addis Ababa University students (37\%) and Tanzanian higher educational students (39\%), and much lower than other study in Aksum University (64.4\%) $[18,19,31-33]$. This may point out that having sex with multiple sexual partners of school adolescents is high and needs attention to change their risk behavior. This signifies that the respondents in Aksum University frequently changed sexual partners. The fact that students who have more sexual partners are valued high may also is a contributory factor for them to have several sexual partners.

In addition to sexual partner/s of adolescents this study also found that, frequency of condom use consistently during sexual intercourse was $62.1 \%$. This finding is lower than the studies done in Gondar high school students, $68.4 \%$ used condom always [34]. This suggests that a significant number of University adolescents in current study are practicing unprotected sex. This was also reflected in their lack of awareness on safe sex practices such as consistent condom use. However, the finding is much higher as compared to a study done in Aksum University which shows that $16.5 \%$ of participants used condom consistently [33]. Low utilization of condom consistently is an indication of the fact that high-risk behaviors are still widely practiced among Aksum University students. This might be due the difference in study period.

The multivariate analysis indicated that, late age at first sexual intercourse, lack of source of information on sexuality, visited night clubs, and didn't receive parental supervision in the 12 months before the survey were the risk factors for having engaged in unprotected sexual practice. In this study per a unit increase in total score of age of participants at first sexual intercourse, the odds of unprotected sex is also increased by 2.5 and the observed difference was statistically significant. A study done in Southern Taiwan and Brazil showed that an increase of one year of age increased the odds of engaging in unsafe sex $[23,35]$. This may indicate that university environment or the notion of being in university makes older youth students more susceptible to risky sexual practices, as they are free from parental control and spend time by visiting night clubs. Supporting this idea, a study done by Le TN and Kato T. reported, developmentally it is expected that older youths would have more opportunity and be more likely to spend time engaging in various behaviors, including risky sex [36].

This study also revealed that majority of adolescents were supervised by their parents and those who didn't receive parental supervision were about 5 times more likely to practice unprotected sex, which is consistent with the results of previous studies [23, 37-40]. Other study done by Crouter et al. reported, parental supervision may directly and indirectly influence the adolescent's likelihood of involving in risk behaviors by imposing limits or expectations on when, where and with whom the youth may recreate [41]. This can be explained because of freedom from direct parental supervision and monitoring give high level of personal freedom and social interactions, which offers an opportunity to express their freedom by practicing sexual activity without protection. Supporting this idea, study done by Iwuagwu SC, Ajuwon AJ, Olasheha IO stated that, higher institutions give high level of personal freedom and social interactions, which offers an opportunity for high level of sexual networking [43]. Indeed, Rosiers, et.al reported, the absence of adult supervision in college settings may exacerbate risky sexual behaviors [28]. In general this finding implied that the importance of parenting on the development of sexuality in the youths, and parents should be included in interventions to reduce adolescent unprotected sex. Meanwhile, the role of parents in promoting adolescent sexual health cannot therefore be overemphasized.

The other important variable of this study was source of information on sexuality, those students who hadn't source of information on sexuality were more likely to practice unprotected sex as compared with those who had source of information and the most frequently mentioned sources of information were media and educational institutions. This indicates that lack of adequate information about sexuality and reproductive health risks which have grave unprotected sex consequences, including HIV/AIDS, STI, unwanted pregnancy and its complications. Previous studies conducted in Ethiopia, the main mentioned sources of information were, media in Debre Birhan, and health professionals in 
Madawalabu University [44, 45]. However study done in Robe TVET students showed that only half of the study participants, $49.9 \%$, were obtaining information of sexuality from media and school [46]. This finding implied that, media, educational, and health institutions are playing an important role in information dissemination on the development of sexuality in the youths and they should be included in interventions to create adolescents' awareness about prevention of unprotected sex and its complications. Besides family and friends play a majority in disseminating information which needs attention that peers may not have the right knowledge or miss informed.

As regards visiting night clubs or parties, only $16.5 \%$ of respondents reported that they visit night clubs/parties and those who visited night clubs/parties were more likely to practice unprotected sex than those who didn't visit. This indicates that adolescents spend spare time with peers by visiting night clubs, and may learn health-risk behaviors, and may makes students more susceptible to risky sexual practices, including unprotected sex. Meanwhile, attending night clubs may have a negative impact on adolescents' safe sex, which may increase the risk of unprotected sex in adolescents. This result is in agreement with findings obtained in previous studies done in Addis Ababa and Mauritius [31, 47]. This might be due to the nightclubs are an important place where sexually experienced young men and women congregate and learn health-risk behaviors.

\section{Conclusion}

Generally, this study revealed that large proportions of adolescent students were sexually active. Of these, significant segment of students had sexual intercourse with their non-regular partner within the last 12 months using condom inconsistently, this suggests that students of Rift Valley University, Jimma campus were practicing unprotected sex which may play an important role in HIV/STI transmission as an indicator of students' vulnerability. It is therefore important to focus prevention efforts on factors promoting unprotected sex.

This study showed, the independent predictors of unprotected sexual practice among students were parental supervision, visiting night club, having source of information on sexuality, and age at first sexual intercourse. These findings mean that students at RVU, Jimma campus who had freedom from parental guidance, lacked information on sexuality, spend spare time by visiting night clubs, initiated sex at the older age when they entered a university were prone to practicing unprotected sexual behaviors. Therefore, university, families and zonal education office and other stakeholders should be involved and working in collaboration to reduce the unprotected sexual practice. Improving parent-student communication on sexual matters and family-university integration would be the best practice and the primary focus for interventions, because family-focused interventions have a positive effect on students' behaviors and well proved strategy to avoid the student's misbehavior like frequent visiting of night club as well as to take responsible in doing any sexual behaviors.

This study had some limitations. Due to the fact that this study deals with very personal and sensitive issues such as sexual practice and other risk factors related to it, obtaining an honest response among adolescent students was difficult. There may be social desirability bias so they may hide the real information. To the extent that in-university adolescents differ from out of university adolescents, these findings may not be applicable to out of university adolescents. Because the study targeted only regular undergraduate students, which was not representative of all university students, the findings therefore should be generalized or extrapolated with caution to other university student groups. Since this was a crosssectional study based on retrospective memory data collection, the possibility of memory recall bias or selective memory recall may have occurred. These could have negatively impacted on research findings. Cross sectional nature of the study precluded determining causal relationship.

Therefore, recommendations were made for the need of further research; to compare unprotected sex of broader sample of students in the private and governmental universities and to assess unprotected sex and determine interventions to minimize it by targeting predictors. In addition, research using both quantitative and qualitative studies to address the personal and sensitive issues of students' sexual behaviors and describe factors facilitating unprotected sex.

\section{Abbreviations}

HIV, Human Immunodeficiency Virus; STI, sexually transmitted infection; AOR, adjusted odds ratio; CI, confidence interval; COR, crude odds ratio; RVU, Rift Valley University; UPSP, Unprotected Sexual Practice; TVET, Technical Education and Vocational Training; ERC, Ethical Review Committee; JTTC, Jimma Teachers Training College; SD, standard deviation; SPSS, Statistical Packages for Social Science; WHO, World Health Organization.

\section{Acknowledgements}

I would like to acknowledge the assistance of the RVU, Jimma campus in undertaking this research. I would also like to express my gratitude to study participants, registrar office workers, and department heads working in RVU Jimma campus that really deserves acknowledgement for their cooperation. Last not least, my thanks also go to data collection facilitators and my friends.

\section{References}

[1] Shittu et al. The negative impacts of adolescent sexuality problems among secondary school students in Oworonshoki Lagos. Scientific Research and Essay January 2007; 2 (1): 023- 028 . 
[2] Dawud A. Perception of the risks of sexual activities among out-of school adolescents in South Gondar Administrative Zone. Amhara Region, 2003.

[3] United Nations Population Fund (UNFPA), State of the World Population 2003: Investing in Adolescents' Health and Rights, New York: UNFPA, 2003

[4] Lloyd CB. Schooling and Adolescent Reproductive Behavior in Developing Countries. 2004.

[5] Wellings $\mathrm{K}$ et al. Sexual behaviour in context: a global perspective. Lancet 2006; 368(9548): 1706-1728.

[6] FMOH. International strategies that work for youth; summary of focus on young adults: End of program report. Ethiopia, 2002

[7] CSA E, International I. Ethiopia Demographic and Health Survey 2011. Addis Ababa, Ethiopia and Calverton, Maryland, USA, 2012

[8] Jimma zone and Jimma town Education Offices, 2011.

[9] Lemma E. Predictors of HIV/AIDS related sexual behavior of high-school adolescents, Jimma town, southwest Ethiopia, 2000

[10] Tadesse E, Gudunfa A, Mengistu G. Survey of adolescent reproductive health in the city of Addis Ababa. Ethiop. J. Health dev., 1996; 10(1):35-39.

[11] Scholl Ed, Schueller J, Gashaw M, Wagaw A, Wolde Michael L. Assessment of Youth Reproductive Health Programs in Ethiopia. FHI for Youth Net, 2004: No. GPH-A-00-01-0001300 .

[12] Katie Dillard. Adolescent Sexual Behavior. II: SocioPsychological Factors. 2002 November.

[13] Central Statistical Agency [Ethiopia] and ORC Macro. Ethiopia Demographic and Health Survey, Governmental Publication, 2007.

[14] Rift Valley University. Wikipedia. Available at: http://riftvalleyuniversity.net/.

[15] MOH, AAU, Central Statistical Agency, \& EPHA. HIV/AIDS behavioral surveillance survey, Ethiopia round 2. Addis Ababa: Government Publication, 2005.

[16] Seme A, Wirtu D. Premarital sexual practice among school adolescents in Nekemte Town, East Wollega, Ethiopia. Ethiop J Health Dev. 2008; 22(2):167-173.

[17] Ibrahim N. Factors that influences school adolescent's exposure to HIV/STD in Bale, Oromia Region. Unpublished Master's thesis. DCH FM, AAU May, 2004:29-30.

[18] Amare H et al. Risky Sexual Behavior and Associated Factors among Adolescent Students in TanaHaik High School, BahirDar, Northern Ethiopia. International Journal of HIV/AIDS Prevention, Education and Behavioural Science 2017; 3(4): 41-47.

[19] Agajie M, Belachew T, Tilahun T, Amentie M. Risky sexual behavior and associated factors among high school Youth in Pawe Woreda Benishangul Gumuz region. Sci J Clin Med 2015; 4: 67-75.

[20] Fatusi AO. Faith Communities and Adolescent Sexual Health Development in HIV/AIDS Era. In Akinrinade S, Kolawole M, Mojola I, Ogungbile (eds). Locating the Local in the Global: Voices on a Globalised Nigeria. 2004.
[21] Dahl RE. Adolescent brain development: a period of vulnerabilities and opportunities. Keynote address. Ann N Y Acad Sci. 2004; 1021:1-22.

[22] Dadi AF, Teklu FG. Risky sexual behavior and associated factors among grade 9-12 students in Humera secondary school, western zone of Tigray, NW Ethiopia. Sci J Public Health. 2014 2: 410-416.

[23] Cheng-Fang Yen, et al. Multidimensional discriminative factors for unprotected sex among adolescents in southern Taiwan. Kaohsiung J Med Sci. April 2009; 25 (4).

[24] Zelalem A, Melkamu B, Muluken A. Risky Sexual Practices and Associated Factors for HIV/AIDS Infection among Private College Students in Bahir Dar City, Northwest Ethiopia. ISRN Public Health. 2013; 9: Article ID 763051.

[25] Tura G, Alemseged F, Dejene S. Risky sexual behavior and predisposing factors among students of Jimma University, Ethiopia. Ethiop J Health Sci. 2012; 22(3):170-80.

[26] Helen A. M, Tesfay T. A. The prevalence of risky sexual behaviors amongst undergraduate students in Jigjiga University, Ethiopia. HEALTH SA GESONDHEID 21 (2016)179-186.

[27] Commission, L. V. B. HIV sero-behavioural study in six Universities in Uganda. 2010.

[28] Rosiers et al. A cultural and social cognitive model of differences in acculturation orientations, alcohol expectancies, and alcohol related risk behaviors among Hispanic college students. Journal of Clinical Psychology. 2012; 00(0), 1-22.

[29] Sabone et al. Perceptions of undergraduate students not participating in HIV/AIDS prevention activities in Botswana. Journal Compilation. 2007; 332-338.

[30] Derese A, Seme A, Misganaw C. Assessment of substance use and risky sexual behavior among Haramaya University students, Ethiopia. Sci J Public Health. 2014; 2(2):102-10.

[31] Gizaw A, Jara D, Ketema K. Risky Sexual Practice and Associated Factors among High School Adolescent in Addis Ababa, Ethiopia. Fam Med MedSci Res. 2014; 3: 141.

[32] Siziya S, Rudatsikira E, Ogwell A. E. O, Muula A. S. Prevalence of sexual intercourse among school-going adolescents in Coast Province, Kenya. Tanzania Health Research Bulletin. 2007; 9(3).

[33] Kebede et al. Assessment of risky sexual behavior and practice among Aksum University students, Shire Campus, Shire Town, Tigray, Ethiopia. BMC Res Notes. 2018; 11:88.

[34] Andargie G et al. Low prevalence of HIV infection, and knowledge, attitude and practice on HIV/AIDS among high school students in Gondar, Northwest Ethiopia. Ethiop. J. Health Dev. 2007; 21(2):179-82.

[35] Sanchez et al. Sexual behavior among high school students in Brazil: alcohol consumption and legal and illegal drug use associated with unprotected sex. Clinics. 2013; 68(4):489-494.

[36] Le TN, Kato T. The role of peer, parent, and culture in risky sexual behavior for Cambodian and Lao/Mien adolescents. J Adolesc Health. 2006; 38:288-96.

[37] Klavs et al. Factors associated with early sexual debut in Slovenia: results of a general population survey. Sexually Transmitted Infection. 2006; 82, 478-483. 
[38] Baker et al. Relationship between perceived parental monitoring and young adolescent girls' sexual and substance use behaviors. J Pediatr Adolesc Gynecol. 1999; 12:17-22.

[39] Cromer et al. Prospective studies of adolescents who choose among levonorgestrel implant (Norplant), medroxyprogesterone acetate (Depo Provera), or the combined oral contraceptive pill as contraception. Pediatrics. 1994; 93:687.

[40] Rosenthal et al. How do family characteristics relate to interpersonal expectations regarding STD acquisition among adolescent girls. Fam System Health. 1996; 14:465.

[41] Crouter et al. Parental monitoring and perceptions of children's school performance and conduct in dual- and single-earner families. Dev Psychol. 1990; 26:649-57.

[42] Mcardle P. Substance use by children and young people. Arch Dis Child. 2004; 89: 701-4.

[43] Iwuagwu SC, Ajuwon AJ, Olasheha IO. Sexual behavior and negotiation of male condoms by female students of the University of Ibadan. Journal of Obstetrics and Gynecology. 2000; 20 (5): 507-513.
[44] Zewdie Z. Assessment of HIV risk perception and condom use among youth in Debre Birhan District, Central Ethiopia. Unpublished Master's thesis. DCH FM, AAU April, 2005:3637.

[45] Benti TT, Kebede A, Negaro AE. Prevalence of premarital sexual practice and associated factors among undergraduate health science students of Madawalabu University, Bale Goba, and South East Ethiopia: institution based cross sectional study. The Pan African Medical Journal. 2015; ISSN 19378688 .

[46] Tololu et al. Premarital sexual practice and associated factors among robe TVET students at robe town, bale zone, Oromia region, southeast Ethiopia. MOJ Public Health. 2017; 5(6):193-203.

[47] Nishimura et al. Sexual behaviors and their correlates among young people in Mauritius: a cross-sectional study. BMC International Health and Human Rights. 2007; 7:8. 